\title{
Breastfeeding practices in occupational castes of Sunsari district of Nepal
}

\author{
SB Singh, S Bhattarai, IS Paudel, VK Khanal, A Ghimire \\ School of Public Health \& Community Medicine \\ B.P Koirala Institute of Health Sciences, Dharan, Nepal
}

\begin{abstract}
Background: Breastfeeding provides unique nutritional, immunological, psychological, child spacing benefits besides being cost effective. Childhood malnutrition remains the common health problem in developing countries. Koeri community, an occupational caste resides mainly in Terai region of Nepal. Adherence to breastfeeding recommendations in many areas of our country is not satisfactory. Objective: To find out breastfeeding practices among mothers in Koeri community in Inaruwa of Sunsari district. Methods: A cross-sectional study was carried out in Koeri community of Inaruwa Municipality. Total of 205 households were visited in two wards of Inaruwa Municipality to enroll 36 eligible mothers of the community in the study. Verbal consent was obtained. Data was collected by interview technique using semi structured questionnaire and observation of breast feeding. Proportion and percentage were calculated. Results: Meheta, Mahato, Khuswaha, Singh and Kamat castes constituted the Koeri community. They were occupationally involved in farming specially producing vegetables. Ninety-four percent newborns were colostrums fed. Breastfeeding was initiated within half an hour by around $30 \%$ of the mothers. Prevalence of exclusively breastfeeding mothers up to six months were $38.9 \%$. Nearly $14 \%$ mothers initiated partial breastfeeding before their babies reached to 4 years. Attachment and positioning of babies during breastfeeding was found satisfactory among $54.2 \%$ and $29.2 \%$ of mothers respectively. Conclusion: Though colostrums feeding to babies is common among the Koeri community, partial breastfeeding is practised before the babies reach four months of age.
\end{abstract}

Keywords: breastfeeding, occupational caste, Nepal

\section{Introduction}

Breast milk is the ideal food for infants. Despite the marked advantages of breast-feeding, its popularity has declined significantly in many parts of the world. ${ }^{1}$ The value of breastfeeding is addressed for both mothers and children by the World Health Organization (WHO) and the American Academy of Pediatrics (AAP). Exclusive breastfeeding is recommended for the first six months of life. The AAP recommends supplemented breastfeeding for at least one year after the age of six months, while WHO recommends the supplemented breastfeeding to be continued up to two years or more. ${ }^{2}$, ${ }^{3}$ Exclusive breast feeding practice has significant impact

Address for Correspondence

Dr Suman Bahadur Singh

Associate Professor

School of Public Health \& Community Medicine

B.P Koirala Institute of Health Sciences, Dharan, Nepal

Email:smnsingh@yahoo.com

on child survival and mortality. ${ }^{4}$

Exclusive breastfeeding rates were $42.5 \%$ in Bangladesh, $46.4 \%$ in India, and $53.1 \%$ in Nepal. The rate of full breastfeeding ranged between $60.6 \%$ and $73.9 \%$. A considerable proportion of infants under 6 months of age had been given plain water, juices, or other non-milk liquids. Infant and young child feeding practices in the South Asia region have not reached the expected levels that are required to achieve a substantial reduction in child mortality. ${ }^{5}$

The prevalence of exclusively breastfeeding at 1, 3 and 6 months were $74 \%, 24 \%$ and $9 \%$, and partial feeding was initiated in $15 \%, 38 \%$ and $79 \%$ babies, respectively in Bhaktapur district of Nepal. ${ }^{6}$

The cultural food taboos and beliefs which are deeply rooted in some communities are found to influence 
breastfeeding practices. ${ }^{7}$ UNICEF, WHO and WABA along with the scientific community strongly recommend initiating breastfeeding within half an hour of birth. Early initiation can prevent $22 \%$ of all deaths among babies below one month in developing countries. ${ }^{8}$

Childhood malnutrition remains the common health problem in developing countries. Koeri community, an occupational caste resides mainly in Terai region of Nepal. They involve in farming. Adherence to breastfeeding recommendations in many areas of our country is a matter of concern. So, the study was carried out to find out breastfeeding practices among mothers in Koeri community in Inaruwa of Sunsari district.

\section{Methods}

A cross-sectional study was carried out in Koeri community of Inaruwa Municipality. Meheta, Mahato, Khuswaha, Singh and Kamat castes constituted Koeri community. Total of 205 households were visited in two wards (number 6 and 8) of Inaruwa Municipality so as to enroll 36 eligible mothers of the community under the study. Verbal consent was obtained.

Data was collected by interview technique using pretested semi-structured questionnaire. Observational check list was used to observe attachment and positioning among the breastfeeding mothers. ${ }^{9}$

Inclusion criteria: The mother belonged to Koeri community with a baby of less than three years of age at the time of visit was included in the study. The mother with a baby continuing to breast fed at the time of visit was included in the study.

Exclusion criteria: Mothers of infants with specific feeding problems (cleft lip or palate, congenital heart disease, severe illness during neonatal period or delayed developmental milestones) were excluded from the study. The mother who was not wiling to participate in the study was excluded from the study.

Breastfeeding was categorized into exclusive and partial breastfeeding. The infant who had received only breast milk from his/her mother or a wet nurse, or expressed breast milk and no other liquids or solids with the exception of drops of syrup consisting of vitamins, mineral supplements or medicines or only breast milk in the 24 hours before the survey was categorized as exclusive breastfeeding. Partial breastfeeding included when infant's feeding included non-breast milk foods such as animal/powdered/condensed milk and/or solid/ semi-solid food (i.e. cereals, vegetables, fruits, lentils or meat). ${ }^{10-12}$ Data was analyzed to find out proportion and percentage.

\section{Results}

Meheta, Mahato, Khuswaha, Singh and Kamat castes constituted the Koeri community. They were occupationally involved in farming specially producing vegetables. All the respondents were Hindus. All the babies were continuing to breastfeeding at the time of interview. Ninety four percent of the mothers in Koeri community gave colostrums to babies.

The age range of the mothers was 18 to 37 years. About $70 \%$ were in the age group of 20 to 29 years. Around $11 \%$ mothers were below 20 years of age. About $78 \%$ of mothers were literate. Institutional delivery was reported by $80.6 \%$ of mothers. About $30 \%$ of the mothers initiated breastfeeding within half hour of delivery. Breastfeeding was initiated by $13.9 \%$ mothers only after 24 hours of delivery. Initiation of breast feeding from half an hour to 24 hours after birth was high (55.5\%) among the mothers. About $19 \%$ of mothers initiating breastfeeding within half an hour after delivery were literate. Initiating breastfeeding within half an hour after delivery in health institution was done by $22.2 \%$ mothers (Table 1 ). 
Table1: Distribution of mothers who started breastfeeding after birth of baby by background characteristics ( $\mathrm{N}=\mathbf{3 6})$

\begin{tabular}{|c|c|c|c|c|}
\hline Characteristics & $\begin{array}{c}\text { First breast fed }<1 / 2 \text { hrs } \\
\text { No. (\%) }\end{array}$ & $\begin{array}{l}\text { 1/2hrs to } 24 \mathrm{hrs} \\
\text { No. (\%) }\end{array}$ & $\begin{array}{l}>24 \mathrm{hrs} \\
\text { No. (\%) }\end{array}$ & $\begin{array}{c}\text { Total } \\
\text { Number (\%) }\end{array}$ \\
\hline \multicolumn{5}{|c|}{ 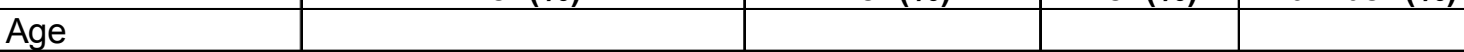 } \\
\hline$<20$ years & $1(2.8)$ & $\begin{array}{ll}2 & (5.5)\end{array}$ & $1(2.8)$ & $4 \quad(11.1)$ \\
\hline $20-30$ years & $7(19.4)$ & $15(41.7)$ & $3(8.3)$ & $25(69.5)$ \\
\hline$\geq 30$ years & $3(8.3)$ & $3 \quad(8.3)$ & $1(2.8)$ & $7 \quad(19.4)$ \\
\hline \multicolumn{5}{|l|}{ literacy } \\
\hline Illiterate & $4(11.1)$ & $\begin{array}{ll}4 & (11.1) \\
\end{array}$ & $0(0)$ & $\begin{array}{ll}8 & (22.2) \\
\end{array}$ \\
\hline literate & $7(19.4)$ & $16(44.4)$ & $5(13.9)$ & $28(77.8)$ \\
\hline \multicolumn{5}{|l|}{ Type of Delivery } \\
\hline Home delivery & $3(8.3)$ & $\begin{array}{ll}3 & (8.3) \\
\end{array}$ & $1(2.8)$ & $\begin{array}{ll}7 & (19.4) \\
\end{array}$ \\
\hline $\begin{array}{l}\text { Institutional } \\
\text { delivery }\end{array}$ & $8(22.2)$ & 17 (47.2) & $4(11.1)$ & $29(80.6)$ \\
\hline
\end{tabular}

Table 2: shows that the proportion of exclusive breastfeeding for the first six months of life was about $39 \%$. About $14 \%$ of babies were partially breastfed before the age of four months. Partial breastfeeding was mostly introduced to babies $(47.2 \%)$ in the age group of 4 to 6 months of age.

\begin{tabular}{|l|c|c|}
\hline Breastfeeding & Frequency (N) & Percentage (\%) \\
\hline $\begin{array}{l}\text { Exclusive } \\
\text { breastfeeding }\end{array}$ & & \\
\hline for 6 months & 14 & 38.9 \\
\hline & & \\
\hline $\begin{array}{l}\text { Partial } \\
\text { breastfeeding }\end{array}$ & & \\
\hline $0-4$ months & 5 & 13.9 \\
\hline 4-6 months & 17 & 47.2 \\
\hline
\end{tabular}

Twelve $(33.3 \%)$ of mothers did not allow to observe the breastfeeding of their babies. Observation of breastfeeding was done to $24(66.7 \%)$ of mothers. Among them attachment of babies during breastfeeding was found satisfactory among $54.2 \%$ of the observed feeding. Positioning of babies during breast feeding was found satisfactory among $29.2 \%$ of the observed feeding (Table 3).

Table 3: Observation on breastfeeding practices. $(\mathrm{n}=\mathbf{2 4})$

\begin{tabular}{|c|c|c|}
\hline \multirow{2}{*}{ Breastfeeding } & \multicolumn{2}{|c|}{ Observed evaluation } \\
\cline { 2 - 3 } & $\begin{array}{c}\text { Satisfactory } \\
\text { No. (\%) }\end{array}$ & $\begin{array}{c}\text { Not satisfactory } \\
\text { No. (\%) }\end{array}$ \\
\hline Attachment & $13(54.2)$ & $11(45.8)$ \\
\hline Positioning & $7(29.2)$ & $17(70.8)$ \\
\hline
\end{tabular}

\section{Discussions}

Meheta, Mahato, Khuswaha, Singh and Kamat castes constituted the Koeri community. Their main occupation is farming, specially producing vegetables. Most of the mothers $(70 \%)$ were in the age group of 20 to 29 years. Proportion of literate mothers (78\%) was higher in our study as compare to the literate women (67\%) in Nepal. ${ }^{13}$

In our study all the babies were continuing to breastfed at the time of interview. Supplemented breastfeeding up to two years or more is recommended. ${ }^{2}$ A Study described that $90.7 \%$ mothers with agricultural occupation breastfed their children beyond the age of 36 months. Mother's age, occupation, education and ethnicity influenced the duration of breast feeding in urban areas of Pokhara, Nepal. ${ }^{14}$ However, the study could only signal a trend of continuation of supplemented breastfeeding among the mothers. Our study was limited only to describe the study variables and the study subjects were the mothers having the babies of less than three years of age.

In the present study, Institutional delivery was reported by $80.6 \%$ of mothers.

In our study, $94 \%$ of the mothers had fed colostrums to babies, comparable to a hospital based study $(95 \%){ }^{15}$ Another study showed that $91 \%$ mothers had fed colostrums to their babies. ${ }^{6}$ Colostrums feeding was popular among the mothers. No other in-depth reasons were asked to the mothers who did not fed colostrums. About $8 \%$ of the mothers who had delivered at home initiated breastfeeding within half hour of delivery, while 
$22.2 \%$ mothers who had delivered in health institution initiated breastfeeding within half hour of delivery. In contrary, a study had shown that

$41.5 \%$ mothers initiated breast feeding within $1 / 2$ hour of birth in a tertiary care center. ${ }^{15}$ The proportion of exclusive breastfeeding for the first six months of life was about $39 \%$ as compare to $53 \%$ finding in the national health survey in $2006 .{ }^{11}$ In contrary, a study conducted in Bhaktapur revealed the substantial low prevalence $(9 \%)$ of exclusively breastfeeding at 6 months. ${ }^{6}$ Only $15 \%$ of infants were exclusively breastfed during first four months of life among schedule caste communities in Haryana, India. ${ }^{16}$

The difference of findings in the studies might be due to different methods used in the researches. Cultural food taboos and beliefs could have explored in our studies. The cultural food taboos and might be the major factors influencing breastfeeding practices.

Partial breastfeeding was mostly introduced to babies before the age of 6 months in our study, while it was initiated mostly at 6 months babies $(79 \%)$ in another study. ${ }^{6}$ Introduction of other foods before six months of age might be due to insufficient breast milk, lack of awareness and characteristics of the families.

Attachment and positioning of babies during breastfeeding was found satisfactory among $54.2 \%$ and $29.2 \%$ of the observed feeding respectively. Inappropriate attachment and positioning during breastfeeding were observed among $60 \%$ mothers by another study. ${ }^{15}$ Appropriate breastfeeding is very important to ensure the feeding of baby. Though continuation of breastfeeding among different communities was revealed in many studies, the techniques to ensure proper breastfeeding were still lacking among the mothers.

Our study was limited to an occupational caste primarily residing in Terai region. Continuation of studies in different communities could result in improvements in breastfeeding practices, preferably prospective studies.

Conclusion

Practice of feeding colostrums is common among the Koeri community. Exclusive breastfeeding for up to six months of age is low. Partial breastfeeding is practiced before the baby reached to four months of age. Practice of inappropriate breastfeeding exists in the community. Promotion and appropriate breastfeeding practice could be improved through the existing healthcare system through ante natal care.

\section{Acknowledgement}

We would like to thank all the mothers and infants who participated in this study.

\section{References}

1. Park K. Feeding of infants. Park's textbook of preventive and social medicine. Edition18.Publisher:M/s Banarsidas Bhanot. Page 39

2. World Health Organization. (2003). Global strategy for infant and young child feeding. http:/ / whqlibdoc. who. int/ publications/ . (assessed 20 November, 2011)

3. Gartner LM, et al. (2005). "Breastfeeding and the use of human milk [policy statement. http:/ / aappolicy. aappublications. org/ cgi/ content/full/ pediatrics

4. Mullany LC, Katz J, Li YM, Khatry SK, LeClerq SC, Darmstadt GL, Tielsch JM: Breast-feeding patterns, time to initiation, and mortality risk among newborns in southern Nepal. J Nutr 2008, 138(3):599-603 27.

5. Dibley MJ, Roy SK, Senarath U, Patel A, Tiwari K, Agho KE, Mihrshahi S; Across-country comparisons of selected infant and young child feeding indicators and associated factors in four South Asian countries. South Asia Infant Feeding Research Network. Food Nutr Bull. 2010 Jun;31(2):366-75. http://www.ncbi.nlm.nih.gov/ pubmed (assessed November 2011)

6. Manjeswori Ula, Ram K Chandyo, Lotta Mellander, Prakash S Shrestha and Tor A Stran Infant feeding practices in Bhaktapur, Nepal: a cross-sectional, health facility based survey International Breastfeeding Journal 2012, 7:1 http:// www.internationalbreastfeedingjournal.com/ (assessed December,2012)

7. Vaahtera M, Kulmala T, Hietanen A, Ndekha M, Cullinan T, Salin ML, Ashorn P: Breastfeeding and complementary feeding practices in rural Malawi. Acta Paediatr 2001, 90(3):328-332.

8. Initiation of breastfeeding by breast crawl. http:// rehydrate.org/breastfeed/index.html (assessed December, 2011) 
9. Vinther T, Helsing E. Breastfeeding- how to support success, A practical guide for health workers. Copenhagen: World Health Organization, Regional Office for Europe; 1997. pp. 10-2.

10. WHO: Indicators for Assessing Infant and Young Child Feeding Practices: Conclusions of a consensus meeting held 6-8 November 2007 in Washington D.C., USA. 2007.

11. Ministry of Health and Population (MOHP), Nepal, NEW ERA and Macro International Inc: Nepal Demographic Health Survey 2006. Kathmandu, Nepal: Ministry of Health and population, New ERA, and Macro International Inc; 2007

12. Labbok MH, Belsey M, Coffin CJ: A call for consistency in defining breast-feeding. Am J Public Health 1997, 87(6):1060-1061.

13. Nepal Demographic and Health Survey 2011 Population Division, Ministry of Health and
Population, Government of Nepal, Kathmandu, Nepal, New ERA Kathmandu, Nepal, ICF International, Calverton, Maryland, U.S.A. March 2012

14. Basnet S, Gauchan E, Malla K, Malla T, Koirala DP, Rao KS, et al. Socio-demographic features of mother in relation to duration of breast feeding in Manipal Teaching Hospital, Pokhara, Nepal. Nepal Journal of Medical Sciences. 2012; 1(1): 27-30.

15. RN Chaudhary, T Shah, S Raja. Knowledge and practice of mothers regarding breast feeding: a hospital based study. Health Renaissance, Vol 9, No 3 (2011)

16. Kapil U, Verma D, Narula S, Nayar D, Sachdev H.P.S., Shah AD, Gnanasekaran N . Breast feeding practices in schedule caste communities in Haryana state. Indian Paediatrics. Volume 31-Oct 1994. Page 1226-1232 